François Gazier, bacharel de Direito، egresso da École Nationale d'Administration -

ENA, professor do Institut International d'Administration Publique-IIAP.

Presidenta.Adjunto do Contencioso do

Conselho de Estado da França.

\title{
A experiência do Conselho de Estado francês
}

O Conselho de Estado é na França uma instituição que surgiu em fins da Idade Média sob a denominação de Conselho do Rei e que, após breve eclipse ao tempo da Revolução Francesa, foi restabelecido em 1800 por Napoleão em sua forma moderna com o nome de Conselho de Estado para, a seguir, varar todos os regimes: monarquias constitucionais, impérios e repúblicas, até os nossos dias.

Essas longinquas origens explicam algumas de suas caracteristicas، à primeira vista, bastante paradoxais.

Concebido como instituição de inspiração autoritária, destinada a auxiliar o poder forte, rel ou imperador, a governar firmemente o pais, o Conselho de Estado. mediante lenta e contínua transformação se tornou, nos tempos atuais, um dos maiores baluartes do liberalismo democrático e dos direitos do homem.

Criado muito antes de Montesquieu e da Declaração dos Direitos do Homem e do Cidadão de 1789, o Conselho de Estado sempre ignorou e continua a ignorar a se- paração dos poderes, colaborando (simultaneamente) com o Legislativo, a Executivo e o Judiciário.

\section{Atribuições}

O Conselho de Estado exerce, fundamentalmente, uma dupla função de conseIheiro e de juiz. Nas áreas do Legislativo e do Executivo atua como um Conselho de Governo. No dominio do Judiciário, se constítui como o Supremo Tribunal Administrativo.

\section{Funçōes consultivas}

A consulta ao Conselho de Estado é obrigatória para todos os projetos de lei que - governo elabora por intermédio de sua administraça e submete ao voto do Parlamento.

É também, obrigatória para a maioria dos decretos elaborados pelos ministros e expedidos pelo Presidente da República ou pelo primeiro-ministro, bem como para um grande número de decisões administrativas de alcance regulatórío e individual. 
Além disso, ao governo é facultado a qualquer momento, consultar o Conselho de Estado sobre textos que está elaborando ou decisōes que pretende tomar, e todos os ministros podem solicitar pareceres sobre quaisquer questões juridicas que lhes pareçam delicadas.

Em todos esses casos, o Conselho de Esrado, estuda os textos que the são submetidos quanto à forma e ao conteúdo, corrige e aperfeiçoa a redação, verifica cuidadosamente a correção jurídica frente à Constituição, às leis e aos regulamentos vigentes e aos principios gerais do Difeito e se preocupa. finalmente, com a oportunidade das medidas propostas, tendo em vista as exigências da boa administração. O Conseltho de Estado evita, no entanto, emitir juizo sobre as ações políticas que os inspiram. Trata-se, na realidade, de uma entidade de assessoramento técnico e não político.

No exercicio dessa função consultiva. convocado a título obrigatório ou facultativo, o Conselho de Estado se limita a emitir um parecer que visa a esclarecer mas nảo a obrigar. O Governo pode ser obrigado a ouvir o Consetho mas não está obrigado a obedecê-lo.

\section{Funçāo jurisdicional}

A França se inclui entre os paises que adotam o sistema de dualidade de jurisdição e osienta duas categorias jurisdicionais paralelas: a judiciária, exercida pelos tribunais ordinários, integrados por magistrados que se pronunciam sobre matéria civil, penal. comercial e trabalhista, e a administrativa, que dirime os litígios entre os cidadãos e as autoridades administrativas.

Os tribunais judiciários sāo organizados segundo uma hierarquia em cujo ápice se situa a Corte de Cassação. Da mesma forma, os tribunais administrativos são submetidos ao controle de uma Corte Suprema: é o
Conselho de Estado que se apresenta, ao mesmo tempo, como tribunal de primeira e última instância para as questões mais importantes, tribunal de apelação dos tribunais administrativos regionais e tribunal de cassação de numerosas jurisdições administrativas especializadas.

Em todos os casos ele se constitui numa jurisdição soberana que não dá pareceres mas, sim, emite sentenças que se impõem, com força de lei. tanto aos cidadãos quanto ao governo e sua administração.

\section{Composiçāo e organização}

O Conselho de Estado é uma entidade autônoma vinculada orçamentariamente, ao Ministério da Justiça.

É composto de um quadro de altos funcionários de carreira cujo efetivo é da ordem de 250 membros e que se divide hierarquicamente em três niveis: na base os auditores, no nivel intermediário os referendários, no topo, os conselheiros de Estado. Seu recrutamento é feito, basicamente, todos os anos, na Escola Nacional de Administração, entre os alunos de melhor classificação. O recrutamento é completado com a nomeação pelo governo de um certo percentual de referendários e de conselheiros: esta é a quota externa. Os membros do Conselho de Estado são regidos por um estatuto especifico.

A promoçăo é assegurada e quase automática. Todos os auditores têm a certeza de se tornarem, ao final de suas carreiras, conselheiros e não se admite competição para a promoção.

Sem serem legalmente inamoviveis, os membros do Conselho de Estado são, na prática, estáveis.

Finalmente, o estatuto dos membros do Conselho de Estado prevê sua designação, durante boa parte de suas carreiras, para 
funçōes fora do Conselho, onde o exercício de altas responsabilidades lhes dá larga prática e amplo conhecimento da administração e de seus problemas.

O Conselho de Estado se divide em cinco seções, integradas, cada uma, por auditores, referendários e conselheiros: de um lado, a Seção do Contencioso, sem dúvida, a mais importante em termos de lotação, que exerce a função de Suprema Corte Administrativa, de outro lado, as quatro seções administrativas que constituem o Conselho do Governo, em matéria legislativa e administrativa, e que são intituladas do Interior, de Obras Públicas, de Finanças e Sociais.

A frente do Conselho de Estado se acha um vice-presidente, escolhido pelo governo dentre os conselheiros. O título de Presidente cabe em principio ao primeiro-ministro, que, de fato, não o exerce jamais.

Todos os membros do Conselho são lotados nas diferentes seçōes de maneira extremamente flexivel e freqüentemente alteradas, existindo norma que prevê dupla lotação simultânea na Seção do Contencioso e em uma das quatro seções administrativas.

\section{Funcionamento}

O funcionamento do Conselho de Estado obedece a regras tradicionais, aperfeiçoadas no curso de sua longa história e que quase nâo diferem daquelas que vigoravam no Conselho Real de Francisco I au de Luís XIV

Todo assunto recebido resulta na abertura de um processo. 'Este processo é distri. buido a urn relator que, num primeiro momento, o estuda só ou em conjunto com representantes da administração, para em seguida apresentar os fatos e suas conclusões a um ou mais colegiados compostos de conselheiros, referendários ou auditores, os quais o analisam e estabelecem o conteúdo do parecer ou da sentença a emitir.

Nas seções administrativas é o governo quem aciona o Conselho de Estado, submetendo-Ihe projetos de lei, de decreto ou de decisão, ou ainda pedidos de pareceres.

O relator estuda o pedido com o auxilio de representantes da administração e re. dige anteprojeto, o qual é discutido e aprovado na seção e, em seguida, se o assunto é de relevância, segundo o relatório daquela Seção, em Assembléia Geral que reune todos os Conselheiros de Estado.

O parecer do Canselho de Estado assume então, em geral, a forma de nova redação do projeto, acrescida, se necessário. de nota que ressalta as observações ou sugestões do Conselho.

$\mathrm{Na}$ Seção do Contencioso estấ os cidadãos que, em geral, acionam o Conselho de Estado por intermédio de pedidos de anulação de decisões administrativas, desde decretos do Presidente da República atế simples decretos municipais (trata-se aqui de recursos por abuso de poderl, ou de condenação do Estado, ou qualquer outra entidade pública a desembolso lé o recurso de plena jurisdiçãol. O processo é, então. instruido, como perante qualquer tribunal, segundo um procedimento contraditório, em seguida distribuído a um relator que o examina e propõe a um colegiado de instrução (subseção) um projeto de sentença. O processo é, em continuidade, passado a um Comissário do Governo, que é um referendário especializado, incumbido, com toda independência, de se pronunciar sobre o direito. A causa é finalmente julgada perante um colegiado maior, ouvido o Comissário do Governo, em sessão pública. A sentença é. finalmente, lida e publicada.

Assim em todas as causas, o processo terá sido integralmente lido e estudado. 
sucessivamente, por três pessoas: o relator. - Comissário do Governo e o Presidente do colegiado de instrução. Este procedimento, extremamente minucioso, garante exame aprofundado e isento de cada causa e assegura a qualidade da justiça exercida. Mas requer muito tempo e o aumento do número de causas submetidas ao Conselho de Estado (cerca de 10 mil por anol faz com que o Conselho de Estado se encontre em crescentes dificuldades para fazer justiça dentro de prazos aceitáveis. Uma justiça extremamente lenta não é mais justiça. Existe ai um problema que se torna preocupante.

\section{O papel do conselho de estado na vida administrativa francesa}

Enquanto órgāo assessor do governo em matéria legislativa e administrativa, o ConseIho de Estado desempenha papel importante como avalista da correçâo li terária e jurídica dos tex̣tos e da coerência governamental.

Enquanto juiz administrativo supremo، ele assegura a controle jurisdicional da administração pública e ao mesmo tempo a elaboração de uma jurisprudência que se constitui numa das mais importantes fontes do Direito Administrativo. Foi durante litígios que dirimiu que o Conselho de Estado lançou os fundamentos e definiu os contornos de todas as teorias do Direito Administrativo moderno: serviço público, obras pú blicas, domínio público, mercados e contratos administrativos, função pública, responsabilidade do poder público. . .

Enfim, a esta atividade que desenvolve o Conselho de Estado enquanto instituição se acrescenta outra, também muito importante, exercida por seus membros a título individual. Além de participarem dos trabalhos do Conselho nas seções administrativas e na Seçāo do Contencioso eles exercem. também, toda uma gama de funçōes de assessoramento na administração e, sobretudo, presidem a um número considerável de comissões, jưris, grupos de estudo e de trabalho.

Enfim, valendo-se, amplamente, da pre vişão estatutária da agregação, eles representam para o governo um contingente de altos funcionários polivalentes, sempre disponiveis para ocupar temporariamente postos de responsabilidade na administração ativa, gabinetes ministeriais, cargos de direção ou de inspeção, missões internacionais, etc. . .

O Conselho de Estado está, assim, por intermédio de seus membros, presente na maioria dos setores da vida governamental e administrativa da França.

\section{Os conselhos de estados fora da Franca}

Existem fora da França numerosos Conselhos de Estado, alguns dos quais nada têm a ver com o Conselho de Estado francês، posto que a denominação abrange realidades bem diversas e é utilizada, em certos paises, para indicar o conjunto do governo.

Mesmo restrita aos Conselhos de Estado de tipo francês, a saber aos órgãos técnicos e não politicos, combinando funções de assessoramento com atividades jurisdicionais. a lista é longa. Napoleão împôs Consel hos de Estado aos paises vizinhos da França por ela dominados: Itálía, Países Baixos, Espanha e Portugal. Alguns deles mais tarde desaparece ram, notadamente em Portugal e no Brasil. que criara um Conselho de Estado ao tempo do Império. Outros sobreviveram ou foram restabelecidos، enquanto certos países، mais recentemente e de forma espontânea, incorporam a fómula francesa, tais como a Grécia، a Turquia، o Libano، o Egito، a Bélgica e, na América Latina, a Colômbia.

Por outra parte, em numerosos países e, em particular, na Africa francofona, sem chegar à criação de verdadeiros Conselhos de 
Estado, foram instituidos Tribunais Administrativos Superiores, ou Câmaras Administrativas das Cortes Supremas, diretamente inspirados na organização e no funcionamento do Conselho de Estado francês. Essa influência é visivel também na Corte de Justiça da Comunidade Econômica Européia, no Luxemburgo.

Por fim. o Conselho de Estado francês exerce uma influência muito difundida, mesmo em países que não possuem qualquer instituição de governo desse gênero, por meio de jurisprudência que elaborou e que, como já foi dito, se situa entre as mais importantes fontes do direito administrativo, não só francês como universal.

Eis, em linhas gerais, o Consellyo de Estado francês, instituição original e complexa, tâo intimamente ligada à história da França que não pode ser transplantada para outro país, mas cujo conhecimento pode ser objeto de úteis ensinamento ou reflexões.

Para terminar, não há como melhor resumir-Ihe a natureza do que citando a célebre fórmula do decano Maurice Hauriou: - Conselho de Estado é a consciência da administração, pois que, como a consciência. ele aconselha e julga. 